\title{
Two sisters with a syndrome of ocular, skeletal, and abdominal abnormalities (OSA syndrome)
}

\author{
Rita Mingarelli, Alessandro Castriota Scanderbeg, Bruno Dallapiccola
}

\begin{abstract}
Two adult sisters are described who had a unique association of facial, ocular, and skeletal defects, and abdominal muscle hypoplasia, indicating autosomal recessive inheritance. Many of these features overlap those previously found in other malformation syndromes. However, the constellation of defects observed in these patients appears to represent a previously unreported syndrome and autosomal recessive inheritance is likely.

(f Med Genet 1996;33:884-886)
\end{abstract}

Key words: blepharophimosis; skeletal defects; autosomal recessive inheritance; OSA syndrome.

Cattedra di Genetica Medica, Università Tor Vergata, Via di Tor Vergata 135, I-00133 Rome, Italy, and CSS

Hospital, San Giovanni Rotondo, Italy

R Mingarelli

A Castriota Scanderbeg

B Dallapiccola

Correspondence to:

Dr Dallapiccola.

Received 12 March 1996 Revised version accepted for publication 30 May 1996

\section{Family history}

The two affected sisters are the first and third sibs, born to healthy parents originating from southern Italy (Calabria). Family pedigree tracing through five generations indicated no parental consanguinity. One brother and one sister are unaffected. The family history is unremarkable.

\section{Case report}

Case 1 was born in 1964 in the 38th week of an uncomplicated pregnancy. Onset of labour was spontaneous and delivery normal. Birth weight
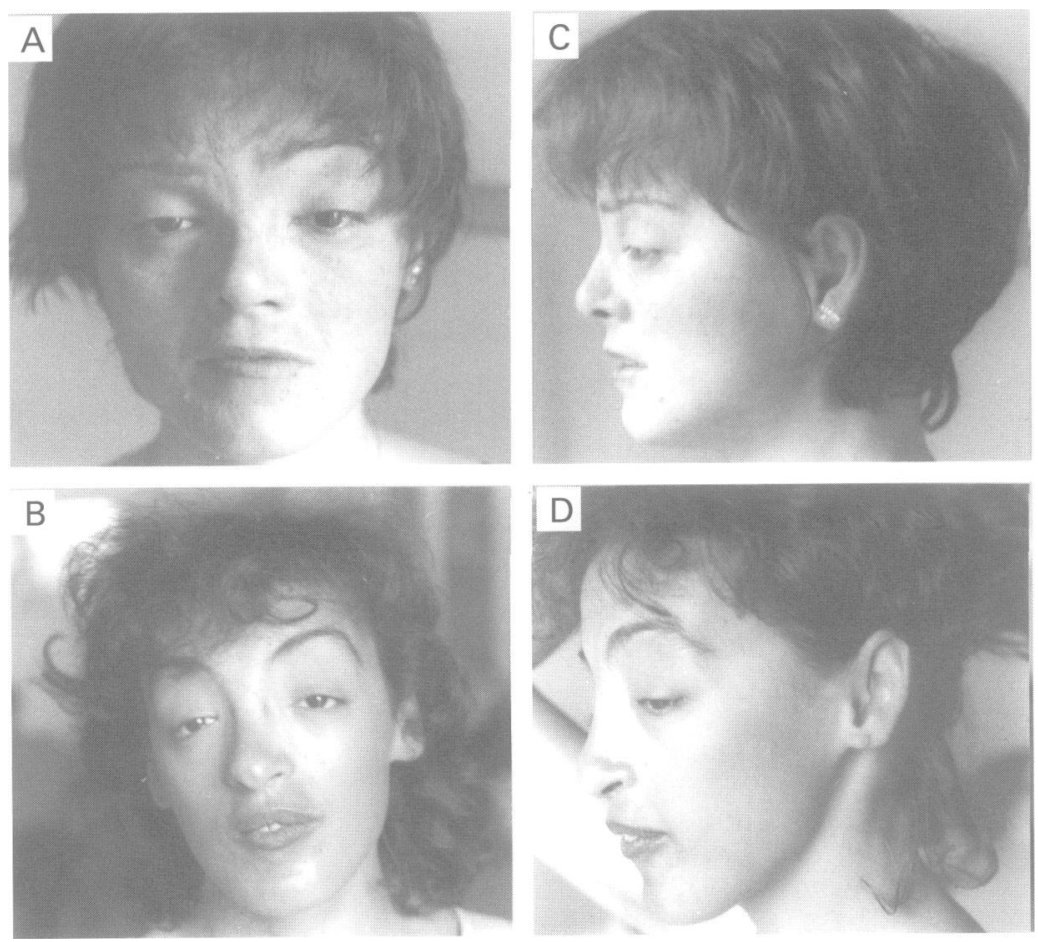

Figure 1 Frontal $(A, B)$ and lateral $(C, D)$ facial appearance of case 1 (upper row) and case 2 (lower row). was $3200 \mathrm{~g}$, length $50 \mathrm{~cm}$, and head circumference (OFC) $33 \mathrm{~cm}$. Gross facial dysmorphism, including highly arched eyebrows, ptosis, epicanthus inversus, and right sided nasal septum, were recorded at birth. Developmental milestones were considered normal. Menarche occurred at 13 years. At the age of 18 years the patient underwent two operations to correct ocular and nasal dysmorphism, but the results were suboptimal. She graduated in theology and at present is a school teacher.

This patient was first seen by us at the age of 30 years, when her brother requested preconceptional genetic counselling. She weighed 47 $\mathrm{kg}$ and her height was $152 \mathrm{~cm}$, well in the range of her parents. Clinical manifestations included receding forehead, arched and thin eyebrows with medial flaring, bilateral blepharophimosis, epicanthus inversus, slightly upward slanted and short palpebral fissures $(2.8 \mathrm{~cm},-2$ SD), medially short eyelashes, increased inner canthal distance $(4.7 \mathrm{~cm},+4 \mathrm{SD})$, right sided nasal septum, flat malar region, smooth and short philtrum (25th centile), gothic palate, and rounded chin (fig 1A, B). The ears were normally set and shaped. There was also diastasis recti owing to hypoplasia of the recti abdominis muscles (fig 2A) extending from their insertion at the xiphoid process to the pubis. She was unable to extend her upper limbs fully or to pronosupinate her hands. Her fingers were rather broad and short with clinodactyly of the fifth fingers. Palmar creases and dermatoglyphics were unremarkable with eight whorls and two ulnar loops on the fingertips and proximally located axial triradii.

On cardiological evaluation there was mild aortic incompetence. Sonography of the abdominal organs was negative. Radiographic investigations of the skull disclosed a thickened cranial vault, a hypoplastic posterior cranial fossa, platybasia, and a short, midline occipital horn. There was also a cleft in the anterior arch of $\mathrm{C} 1$, thoracolumbar rotatory scoliosis, extensive lumbosacral spina bifida, and hypoplasia of the 12th right rib. The pelvis was squared, with flaring of the iliac wings (fig 2B). The upper limbs showed proximal radioulnar synostosis with a posteriorly dislocated radial head (fig 2C). MRI and CT scans disclosed an empty sella and widening of the inner ear vestibulum and external semicircular canals.

Routine laboratory studies, including urine analysis, blood count, serum chemistries, plasma and urine amino acids, and assessment of pituitary, thyroid, and adrenal gland function, were normal. Standard and high resolution chromosome analysis was also normal. 

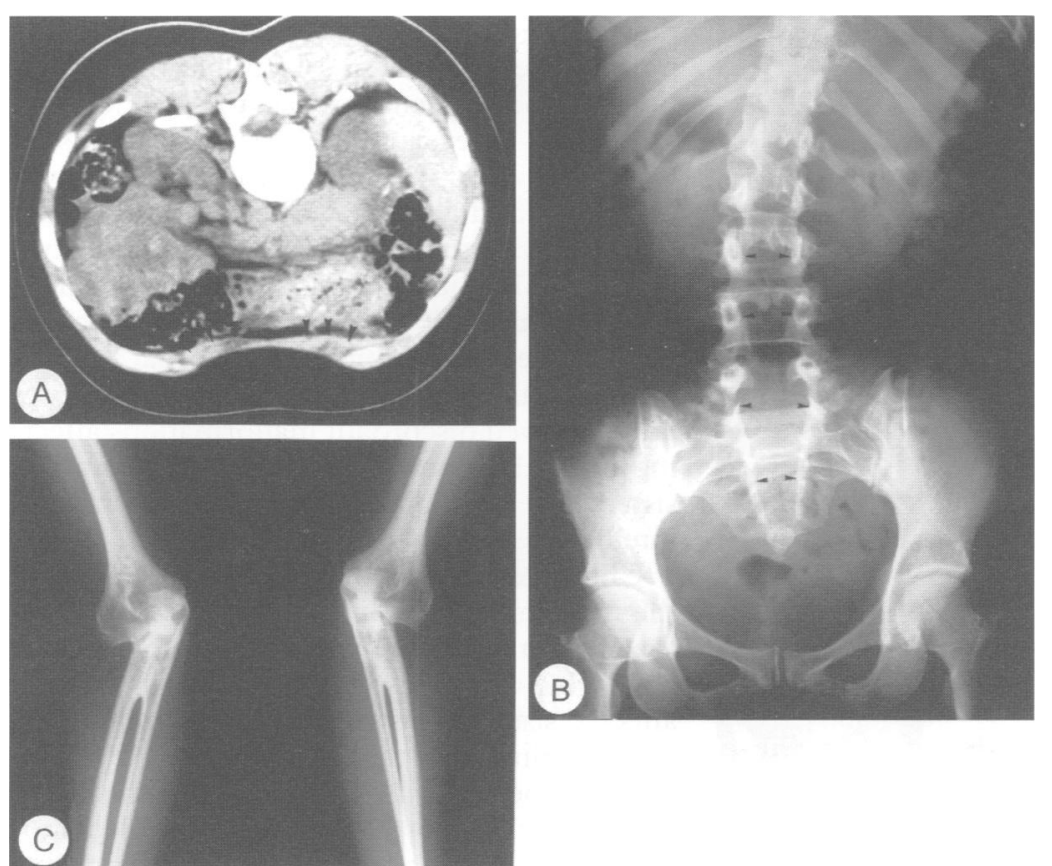

Figure 2 Case 1.CT scan of the abdomen showing marked hypoplasia of recti (arrowheads) (A), thoracolumbar rotatory scoliosis, hypoplasia of the 12th right rib, extensive lumbosacral spina bifida (arrowheads), and square shaped pelvis (B), and proximal bilateral radioulnar synostosis $(C)$.

Case 2 was born in 1968 by spontaneous delivery in the 38th week of an uneventful pregnancy. Birth weight was $3600 \mathrm{~g}$, length 50 $\mathrm{cm}$, and OFC $33 \mathrm{~cm}$. The same facial dysmorphism as found in her older sister was recorded at birth. The neonatal period was unremarkable and developmental milestones were normal. She suffered recurrent middle ear infec-

Table 1 Summary of clinical manifestations in the patients of Carnevale et al ${ }^{1}$ and in the present patients

\begin{tabular}{|c|c|c|c|c|}
\hline Clinical manifestations & $\begin{array}{l}\text { Carnevale et } \\
\text { al } l^{1} \text { Patient } 1\end{array}$ & $\begin{array}{l}\text { Carnevale et } \\
\text { al }{ }^{l} \text { Patient } 2\end{array}$ & $\begin{array}{l}\text { This report } \\
\text { Patient } 1\end{array}$ & $\begin{array}{l}\text { This report } \\
\text { Patient } 2\end{array}$ \\
\hline Sex & $\mathbf{M}$ & $\mathbf{M}$ & $\mathrm{F}$ & $\mathbf{F}$ \\
\hline Gestation (wk) & 32 & 28 & 38 & 38 \\
\hline Birth weight $(\mathrm{g})$ & 3200 & 2400 & 3200 & 3800 \\
\hline Asymmetrical head & + & - & - & + \\
\hline Synophrys & + & - & - & - \\
\hline Palpebral slant & Down & Down & Up (operation) & Down \\
\hline Blepharophimosis & + & + & + & + \\
\hline Epicanthus inversus & + & + & + & + \\
\hline Hypertelorism & + & + & + & + \\
\hline Dystopia canthi & - & - & + & + \\
\hline Strabismus & + & + & - & + \\
\hline Depressed nasal bridge & + & + & - & - \\
\hline Simple philtrum & + & + & + & + \\
\hline Downturned mouth corners & + & + & - & - \\
\hline Gothic palate & + & + & + & + \\
\hline Dental caries & + & + & - & - \\
\hline Malocclusion & - & - & + & + \\
\hline Low set, dysplastic ears & + & + & - & - \\
\hline Narrow auditory canals & + & + & - & - \\
\hline Middle ear infections & - & + & - & + \\
\hline Enlarged semicircular canals & + & - & + & + \\
\hline Accessory, widely spaced nipples & + & - & - & - \\
\hline Hypoplastic abdominal muscle & + & + & + & + \\
\hline Limited elbow extension & + & + & + & - \\
\hline Hip dysplasia & + & + & - & - \\
\hline Platybasia & - & - & + & + \\
\hline Short posterior cranial fossa & - & - & + & + \\
\hline Occipital horn & - & - & + & + \\
\hline CNS anomalies & - & + & + & + \\
\hline Scoliosis & - & - & + & + \\
\hline Lumbosacral spina bifida & - & - & + & + \\
\hline Radioulnar synostosis & - & - & + & - \\
\hline Carpal fusion & - & - & - & + \\
\hline Hyperreflexia & + & + & - & + \\
\hline Mental retardation & + & + & - & - \\
\hline Short stature & + & + & - & - \\
\hline
\end{tabular}

tions. Menarche occurred at the age of 13 years. She achieved a high school certificate.

This patient was evaluated by us, together with her sister, at the age of 27 years, when her weight was $46 \mathrm{~kg}$ and height $158 \mathrm{~cm}$. Unlike her older sister, she had not undergone facial plastic surgery, but her general appearance was similar (fig 1C, D). The skull was mildly dolichocephalic, with a flat and receding forehead. The face was asymmetrical and elongated, with a flat malar region, prominent glabella and nasal root, left sided nasal septum, hypoplastic nasal alar cartilages, rounded and bifid nasal tip, and large, asymmetrical nostrils. Her eyebrows were long, thin, and high arched. The palpebral fissures were short $(3.1 \mathrm{~cm},-1$ SD) and downward slanting, with bilateral blepharophimosis, increased inner canthal distance $(5.1 \mathrm{~cm},+2 \mathrm{SD})$, epicanthus inversus, and convergent strabismus. A somewhat smooth and short philtrum $(0.9 \mathrm{~cm}, 3 \mathrm{rd}-25$ th centile) was present. The mouth was small with prominent mucosa of the upper and lower lips. The palate was high arched with impacted teeth, and the chin was rounded. The ears were normally set, but slanted. There was a striking abdominal hollow owing to marked muscular hypoplasia. The upper limbs were normal with no limitation of pronosupination. The dermatoglyphic fingertip pattern consisted of eight whorls and two ulnar loops.

Radiographic findings included an abnormal skull configuration, with severe hypoplasia of the posterior cranial fossa, platybasia, marked thickening of the calvarium, and a midline occipital horn (fig 3A). The spine showed basilar invagination with fusion between the atlas and the occiput, mild thoracolumbar rotatory scoliosis, and extensive lumbosacral spina bifida. The pelvis was square with flaring of the iliac wings. There were carpal fusions between the lunate and triquetrum and capitate and hamate bilaterally, and between the trapezium and trapezoid on the left (fig 3B), and mild shortening of the proximal and middle phalanges. CT and MRI scans disclosed widening of the vestibulum and external semicircular canals. In addition, there was a mild compression of the upper cervical cord owing to basilar invagination and a downward displacement of the fourth ventricle and cerebellar tonsils extending to $\mathrm{C} 3$ (Arnold Chiari type 2) (fig 3C).

Cardiovascular evaluation was normal. Sonography of the abdominal organs was negative. Results of biochemical investigations, including amino acid analysis, oligosaccharide chromatography, and karyotype, were normal.

\section{Discussion}

The association between ptosis of the eyelids, diastasis recti, and a number of additional clinical features, including skeletal defects, developmental delay, and mental retardation, was reported by Carnevale et al in two brothers born to parents who were first cousins once removed. They showed quite distinct ocular findings with hypertelorism, downward slanting palpebral fissures, blepharophimosis, epicanthus inversus, limitation of upward gaze, 

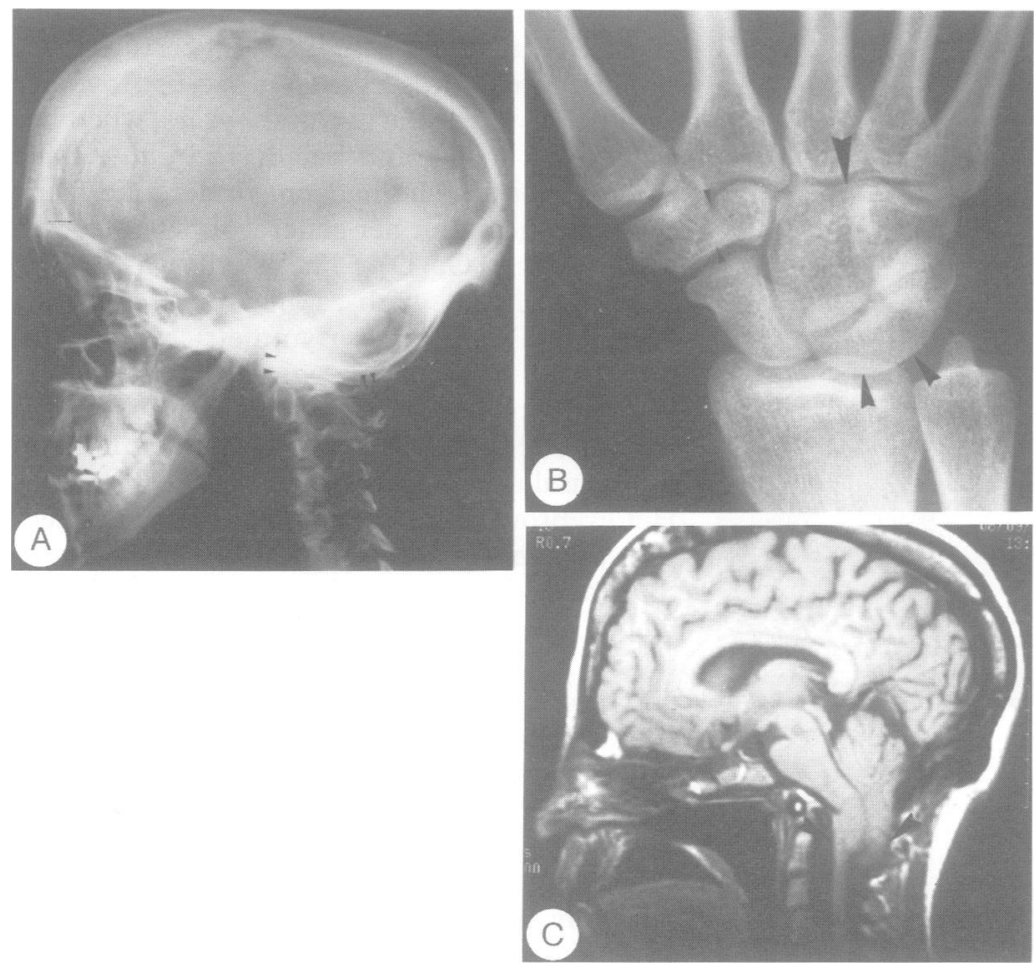

Figure 3 Case 2. Severe hypoplasia of the posterior cranial fossa, platybasia, thickening of the calvarium, and basilar invagination with occipitalisation of $C 1$ (arrowheads) (A); left hand fusion between trapezium and trapezoid (small arrowheads), lunate and triquetrum (medium arrowheads), and capitate and hamate (large arrowheads) (B); midline sagittal MRI scan showing brain stem and cerebellar tonsils extending down to C3 (arrowheads) and a mild compression of the upper cervical cord, owing to basilar invagination $(C)$.

and strabismus. The patients also had a depressed nasal bridge, high arched palate, low set and malformed ears with asymmetrically narrowed external auditory canals, partial agenesis of the abdominal muscles, limitation of elbow extension, hip dysplasia, growth deficiency, and retarded psychomotor development. Many of these features have been observed in the two patients reported here (table 1). Although the first born sister underwent plastic surgery, her facial dysmorphism is similar to that in the other affected sib, apart from the slant of the palpebral fissures. Unlike the patients studied by Carnevale et al, ${ }^{1}$ our patients did not have a depressed nasal bridge, and the mouth, rather than being large with downturned corners, was small. The ears were normally set and not grossly dysplastic. Limitation of elbow extension was a feature only in our older sister and, unlike the patients of Carnevale et $a l{ }^{1}{ }^{1}$ was related to radioulnar synostosis. In addition, while skeletal involvement was limited to hip dysplasia in the two brothers, in our sisters there were gross radiological skull changes, inner ear abnormalities, defects affecting the proximal and distal spine, and a dysmorphic pelvis. The upper limbs showed discordant malformations affecting either the elbows or hands. Finally, our two sisters have normal psychomotor development, intelligence, and stature.

Clinical evaluation of unaffected members in the present family, including a radiological skeletal survey in the parents, did not disclose any of the distinguishing features found in the affected sisters. This supports autosomal recessive inheritance of this association.

A number of symptoms found in these two sisters overlap those encountered in blepharophimosis, ptosis, epicanthus inversus syndrome (BPES), ${ }^{2}$ Lehman syndrome, ${ }^{3}$ Teebi hypertelorism syndrome, ${ }^{4}$ and in two sibs reported by Morillo-Gucci et al. ${ }^{5}$ However, autosomal dominant inheritance and the constellation of associated features unambiguously distinguish these disorders from the condition found in the present patients.

Based on the main clinical manifestations, we designate the association described here ocular-skeletal-abdominal (OSA) syndrome.

1 Carnevale F, Krajewska G, Fischetto R, Grego MG, Bonvino A. Ptosis of eyelids, strabismus, diastasis recti, hip defect, cryptorchidism, and developmental delay in two sibs. Am f Med Genet 1989;33:186-9.

2 Oley C, Baraitser M. Blepharophimosis, ptosis, epicanthus inversus syndrome (BPES syndrome). $\mathcal{F}$ Med Genet 1988; 25:47-51

3 Philip N, Andrac L, Moncla A, et al. Multiple lateral meningoceles, distinctive facies and skeletal anomalies: a new
case of Lehman syndrome. Clin Dysmorphol 1995;4:34751

4 Toriello HV, Delp K. Teebi hypertelorism syndrome: report of a third family. Clin Dysmorphol 1994;3:335-9.

5 Morillo-Gucci G, Passarge E, Simpson JL, Chaganti RSK, German J. Two male sibs with a previously unrecognized syndrome: facial dysmorphia, hyperextensibility of joints, clinodactyly, growth retardation and mental retardation. Birth Defects 1975;11(2):380-3. 